\title{
Biphosphonate in Locally Advanced Breast Cancer
}

\author{
S Sakhri* \\ Medical Oncology Department, Africa \\ Submission: October 02, 2016; Published: October 18, 2016 \\ ${ }^{*}$ Corresponding author: Selma Sakhri, Medical Oncology Department, Algeria hospital, algeria 10, rue docteur saadane, Africa
}

\begin{abstract}
Introduction: Clinical studies have demonstrated synergistic antitumor effects of chemotherapy (CT) and zoledronic acid (AZ). In the essay Neo - AZURE, to determine whether the addition of AZ to neoadjuvant chemotherapy gives compléte histological responses. We report a prospective evaluation comparing compléte pathological response between different subs - biomolecular groups.

Methods: from 2012 to 2014, 432 patients received neoadjuvant chemotherapy + AZ. The main objective is the complete histologic response. Secondary endpoints were clinical response according to RECIST criteria, estimate the overall survival of patients targeted by the study, assess bone density before and at the end of chemotherapy, the side effects associated with the treatment protocol, and Quality life

Results: histologic complete response with zoledronic acid was $40.13 \%$.the higher in the subgroup Her2 / luminal (RH \pm Her2 +) and under Her2 + (HR-Her2 +) and the lowest rate was observed in the triple negative group as classified by Sataloff, overall survival was 45.77 months for subgroups (Her2 / luminal and in Her2 + group) vs 44.11 months for triple negative group.

Conclusion: These data suggest a possible direct antitumor effect of AZ in combination with CT. The studies were recently published in the Proceedings of the American Academy of Sciences (PNAS) shows that bisphosphonates namely zoledronic acid the ability to block the abnormal growth of signals transmitted via the HER receptors, these studies demonstrated that the same can inhibit zoledronic acid tyrosine kinases in case of secondary transfer and thereby potentiate and treat breast cancer became resistant primary treatment.
\end{abstract}

Keywords: Antitumor activity; Breast cancer; Neoadjuvant chemotherapy; PCR; Zoledronic acid

Abbreviations: CT: Chemotherapy; AZ: zoledronic acid; PNAS: Proceedings of the American Academy of Sciences; OPG: Osteoprotegerin; BMI: Body Mass Index; pCR: Pathological Complete Response

\section{Introduction}

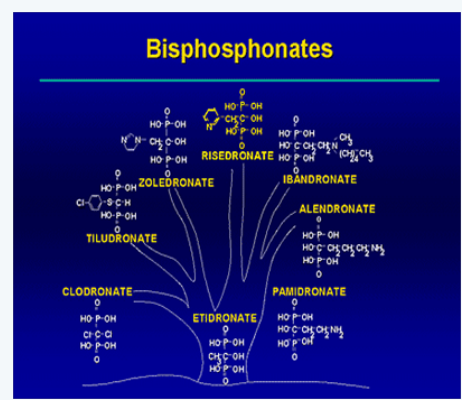

Figure 1: Structure of bisphosphonates.

Bisphosphonate (zoledronic acid) are pharmacological agents that inhibit the activity of osteoclasts. These are desanaloguesstructurelsdu pyrophosphate. Sur terms of their chemical structure, the bisphosphonate are all characterized by the existence of two phosphate groups bound to a central carbon atom, thereby forming a complex p- c- p. Chaînes latérales two
(R1 and R2) are bonded to carbon $\mathrm{p}-\mathrm{c}-\mathrm{p}$ structure by covalent bonds. P -c -p structure and the chain (generally a hydroxyl group) allow the formation of a complex with hydroxyapatite crystals, giving bisphosphonates very high affinity for bone mineral. R2 is the side chain responsible for the inhibitory activity of bisphosphonates on osteoclast (Figure 1).

Zoledronic acid (AZ) (bisphosphonate) acts directly on the tumor cells by blocking the prenylation of G proteins (Ras, Rho) and accumulation in the IPP cells of APPPI. Ras proteins and Rho involved in different signaling pathways that regulate adhesion, migration, invasion and cell proliferation. Inhibition of these cellular functions by AZ has been described in breast cancer.

In vitro it exerts antitumor activity by altering the expression of TRAIL (TNF-related apoptosis-inducing ligand) and that of osteoprotegerin (OPG) in human breast cancer cells (MCF-7, MDA-MB 231), which makes these tumor cells more susceptible to undergo apoptosis. Another function inhibits endothelial 


\section{Cancer Therapy \& Oncology International Journal}

cells by blocking adhesion, migration and survival of these cells. This inhibition is due to the fact that the AZ interferes with the prenylation of different GTPases (Ras, Rho) and phosphorylation of various kinases (FAK, INK, ROCK) (Figure 2).

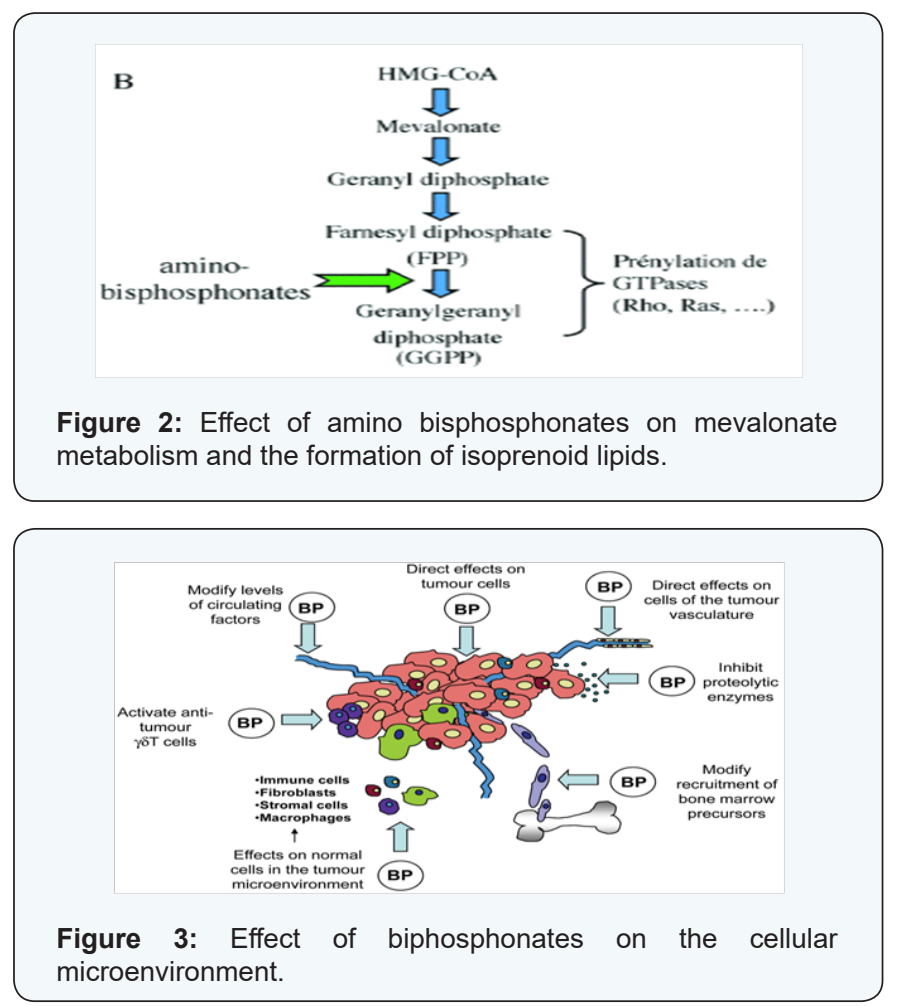

Zoledronic acid inhibits the function of endothelial cells in vitro by blocking adhesion, migration and survival of these cells. This inhibition of endothelial cell functions by zoledronic acid is due to the fact that it interferes with the prenylation of different GTPases (Ras, RhoA) with the phosphorylation of various kinases (FAK, INK, ROCK). In vivo, zoledronic acid blocking tumor angiogenesis (Figure 3) déprivant in the tumor in an essential growth factor for endothelial cells: VEGF. This deprivation is due to the fact that the AZ inhibits infiltration of tumors by macrophages, thereby limiting the degradation of extracellular matrix by proteases secreted macrophages and, thereby, blocking the release of VEGF matrix of Moreover AZ VEGF significantly reduces circulating levels in patients with metastatic breast cancer. in addition, patients with metastatic breast cancer who have circulating VEGF levels decreased in response to a treatment with $\mathrm{AZ}$ have a significantly decreased risk of relapse in comparison with patients whose circulating VEGF levels remain unchanged after treatment with bisphosphonate. These clinical results therefore suggest that AZ could exert antitumor activity through their anti-angiogenic.

Several preclinical and clinical studies [1-3] (Figure 4) demonstrate that the $\mathrm{AZ}$ stimulates the expansion and activation of $\gamma \delta \mathrm{T}$ human lymphocytes when administered in the presence of low doses of IL-2. AZ also stimulates the cytotoxic activity of human T cells $\gamma \delta$ to a wide variety of tumor cells in vitro. In vivo, $\mathrm{AZ}$ enhances the antitumor activity of lymphocytes T human $\gamma \delta$ a recent study also showed a long $\mathrm{T}$. la activation potentiation of antitumour properties lymphocytes T lymphocytes $v \gamma 9 \mathrm{v} \delta 2$ by using a pharmacological approach seems AZ be promising and further studies are ongoing to further characterize the clinical implications of this activation. studies recently published in the Proceedings of the American Academy of Sciences (PNAS) shows that bisphosphonates zoledronic acid namely the ability to block the abnormal growth signals transmitted via the Her receptor (Her1, Her2, Her3, Her4) through which passes an abnormal growth signal, these studies showed that zoledronic acid can inhibit the tyrosine kinase even in case of secondary mutation and thus potentiate and treat breast cancer become resistant to primary treatment.

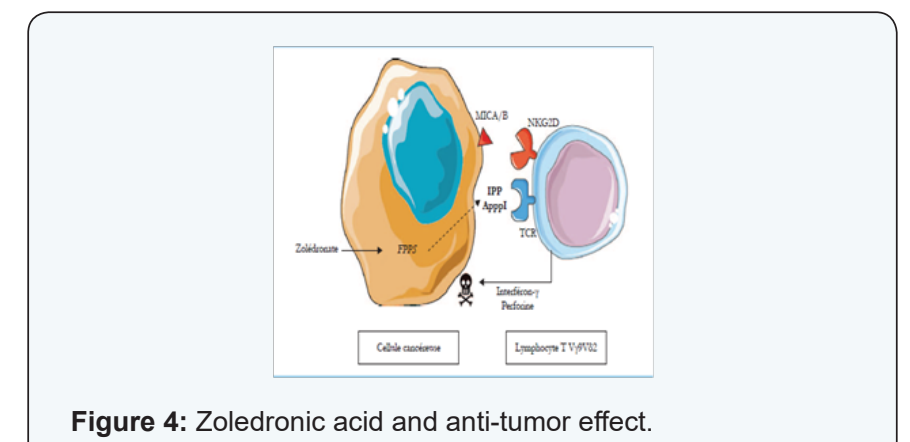

\section{Methods}

From 2012 to 2014, 438 patients were included respondents the inclusion criteria. This is a prospective study over a period of 3 years. Of all patients ( $\mathrm{N}=438), 432$ received neoadjuvant chemotherapy and zoledronic acid. Six of them have progressed after chemotherapy treatments and 04 are excluded from the study, at the end of neoadjuvant chemotherapy, a patient refused surgery therefore no assessment of pCR in this patient who is the main objective of our study, a total of 7 patients study outputs, so it remains 431 who have had a mastectomy with lymph node dissection seen the very advanced stage of the tumor (IIIA, IIIB, IIIC) and the appointment of delay Involved in the period radiotherapy ( 7 - 15 month). No conservative treatment has been practiced. The median follow-up of patients was 42 months.

L'analyse Was done with SPSS 14 software, Patient characteristics are presented with the classical methods of descriptive statistics: frequencies and percentages for categorical variables, medians, extreme values for continuous variables. The association between $\mathrm{pCR}$ and the characteristics of the tumor is assessed using a chi-square test 2. Overall survival was estimated by the Kaplan-Meier method, taking into account the time from the date of chemotherapy, it is defined as the time from the first cycle of chemotherapy and death from any Cause. It is compared among groups using the log-rank test with significance limit of 0.05 . 


\section{Cancer Therapy \& Oncology International Journal}

\section{Primary objective}

Determine the pathological complete response (pCR) in women with locally advanced breast cancer, neoadjuvant chemotherapy placed under Type 04 (doxorubicin + cyclophosphamide) and 04 (Docetaxel \pm Trastuzumab) associated with zoledronic acid.

\section{Secondary objectives}

To evaluate the clinical response according to RECIST criteria. Estimate the overall survival of patients targeted by the study. Evaluate bone density before and at the end of chemotherapy as well as side effects associated with the therapeutic protocol and the quality of life.

\section{Result}

Table 1: Pathological complete response.

\begin{tabular}{|c|c|c|}
\hline \multirow{2}{*}{$\begin{array}{c}\text { PCR } \text { (Tumeur + GCR } \\
\text { N }=258(60 \%)\end{array}$} & $\begin{array}{c}\text { complete tumor } \\
\text { response }\end{array}$ & $64(24,8) \%$ \\
\cline { 2 - 3 } & $\begin{array}{c}\text { complete nodal } \\
\text { response }\end{array}$ & $74(28,6) \%$ \\
\hline No histological response (TDND) & \multicolumn{2}{|c|}{$120(46,5 \%)$} \\
\hline
\end{tabular}

GG: nodes $($ TANA $)=$ TA: histologic complete response, complete response node NA.

(TDND): TD: absence of histological response, ND: no response on the nodes.

Of the 431 patients studied, $173(40.13 \%)$ had a complete pathologic response ( $\mathrm{pCR})$.

The pathologic complete response rate was $40.13 \%$ according to classification Sataloff (1995) .We found that the pathologic complete response rate (Table 1) was the highest in the subgroup (Her2 / luminal) and (Her2 +) and the lowest rate in the triple negative group as classified by Sataloff. These results are consistent with a single study of literature is the study Rouzier [4] where the pathological complete response to neoadjuvant chemotherapy in patients who overexpressed Her2 + is obtained even in the absence of trastuzumab. This leaves suggest that the answer is guided by specific biological factors in Her2 + tumors and zoledronic acid may play a role in inhibiting tyrosine kinases with its potentiation of treatment. Thus the triple negative patients are insensitive to zoledronic acid neoadjuvant.

The Objective response rate was $97 \%$ after (C4) with $3 \%$ stabilizations and $99,3 \%$ of which $0.7 \%$ C8 after stabilization. The clinical complete response was $28 \%$ after $\mathrm{C} 4$ respectively, and $46.8 \%$ after C8. Total 3456 neoadjuvant chemotherapy cycles associated with zoledronic acid was administered to patients in neoadjuvant. treatment postponements occurred in 29 cycles (due to febrile neutropenia + hypocalcemia) no decrease doses was performed. Hematological toxicity of the most common grade I and II was leukopenia. It represents 31, $48 \%$ of cycles. Neutropenia was observed in $28.7 \%$ of cycles and febrile neutropenia (Table 2,3) was observed in $0.5 \%$ of cycles. Hypocalcemia was around de 7,8\% more compared to the literature study (Neozotac) [5] of the order of $0.6 \%$.One patient experienced renal failure grade II with dose reduction of $3.5 \mathrm{mg}$ (Table 4) 5172 adjuvant zoledronic acid cures were administered to patients over 03 years.

Table 2: Hematologic Toxicity.

\begin{tabular}{|l|l|l|}
\hline & Grade 1 et 2 & Grade 3 ou 4 \\
\hline Leucopénie & $\begin{array}{l}31,48 \%(\mathrm{n}=108) \\
\text { (grade I) }\end{array}$ & \\
\hline Neutropénie & $\begin{array}{l}28,7 \%(\mathrm{n}=99) \\
\text { (grade I) }\end{array}$ & $\begin{array}{l}0,5 \%(\mathrm{n}=2) \\
\text { (grade III) }\end{array}$ \\
\hline Neutropénie fébrile & $\begin{array}{l}7,87 \%(\mathrm{n}=27) \\
\text { (grade I, II) }\end{array}$ & $\begin{array}{l}11,57 \%(\mathrm{n}=40) \\
\text { (grade I) }\end{array}$ \\
\hline Thromie & & \\
\hline
\end{tabular}

Table 3: Non-hematologic toxicity.

\begin{tabular}{|c|c|c|}
\hline Effets secondaires & Grade 1 et $\mathbf{2}$ & Grade 3 et 4 \\
\hline Nausées & $18 \%(\mathrm{n}=62)$ & \\
\hline Mucite & $2 \%(\mathrm{n}=7)$ & \\
\hline Constipation & $4 \%(\mathrm{n}=14)$ & \\
\hline Asthénie & $5 \%(\mathrm{n}=17)$ & \\
\hline Anorexie & $9,2 \%(\mathrm{n}=31)$ & \\
\hline Alopécie & $8 \%(\mathrm{n}=29)$ & $92 \%(\mathrm{n}=316)$ \\
\hline $\begin{array}{c}\text { Toxicités des } \\
\text { phanères }\end{array}$ & $1 \%(\mathrm{n}=6)$ & \\
\hline Neuropathie & $6 \%(\mathrm{n}=20)$ & \\
\hline Cardiaque & 0 & \\
\hline Myalgies & $6 \%(\mathrm{n}=20)$ & \\
\hline
\end{tabular}

Table 4: Toxicity related to zoledronic acid during chemotherapy.

\begin{tabular}{|c|c|c|}
\hline Effets secondaires & Grade I-II & Grade III-IV \\
\hline $\begin{array}{c}\text { Ostéonécrose de la } \\
\text { mâchoire }\end{array}$ & 0 & 0 \\
\hline $\begin{array}{c}\text { Syndrome pseudo } \\
\text { grippal }\end{array}$ & 0 & 0 \\
\hline Algies osseuses & $7,8 \%(27)$ & \\
\hline Hypocalcémie & $7,8 \%(27)$ & \\
\hline Insuffisance rénal & $0,2 \%(1)^{*}$ & \\
\hline
\end{tabular}

* = acide zoledronique à $3,5 \mathrm{mg}$

Of Processing reports related to hypocalcemia occurred in 5 cures; no dose reduction was performed. Zoledronic acid was well tolerated with no renal failure and osteonecrosis of the jaw in adjuvant (Table 5). Among the predictors studied we find as a predictor of pathologic complete response without estrogen receptors, the SBR grade III, and overexpression of Her2 (Table 7-9). These results are consistent with the literature [5]. Tumor size has been described as a predictor, after the analysis there was a nonsignificant trend. Another predictor is clinical, is that 


\section{Cancer Therapy \& Oncology International Journal}

of the body mass index (BMI) was correlated with a better pCR with $68.2 \%$ in normal patients $(\mathrm{p}=0.006)$, and zero in obese patients. This has been described in the literature [5]. Among the prognostic factors, we found that the pathologic complete response was correlated with better survival without relapse according to the classification of Sataloff.

Table 7: Correlation between pCR, type and histological grade.

\begin{tabular}{|c|c|c|c|}
\hline Histology & N (\%) & pCR, $\mathbf{n}$ & P= 0.001 \\
\hline CCI & $350(81,01)$ & $160(92,5)$ & \\
\hline CLI & $55(12,73)$ & $7(4,04)$ & \\
\hline $\begin{array}{c}\text { other } \\
\text { carcinoma }\end{array}$ & $27(6,25)$ & $6(3,46)$ & \\
\hline \multicolumn{3}{|c|}{ SBR grading } \\
\hline SBR 1 & $45(10,4)$ & 0.009 \\
\hline SBR 2 & $224(51,8)$ & $8(4,6)$ & \\
\hline SBR 3 & $163(37,7)$ & $165(95,4)$ & \\
\hline
\end{tabular}

CCI: Invasive Ductal Carcinoma; CLI: Invasive Lobular Carcinoma; SBR: Scarff Bloom Richardson

Table 8: Corrélation entre la $\mathrm{pCR}$ et les récepteurs hormonaux.

\begin{tabular}{|c|c|c|c|}
\hline \multicolumn{3}{|c|}{ Hormone Receptors } & $\mathrm{P}=0.01$ \\
\hline HR- & $245(56,7)$ & $116(67,05)$ & \\
\hline HR+ & $187(43,28)$ & $57(32,57)$ & \\
\hline ER-PR- & $245(56,7)$ & $116(67,05)$ & $\mathrm{P}=0.01$ \\
\hline ER+PR+ & $62(14,35)$ & $11(6,35)$ & \\
\hline ER-PR+ & $1(0,23)$ & 1 & \\
\hline ER+PR- & $124(28,7)$ & $45(26,01)$ & \\
\hline
\end{tabular}

RH: Hormone Receptor ; RP: Recepteurs à la Progestérone; RE: Recepteurs aux OEstrogènes

Table 9: Correlation between $\mathrm{pCR}$ and Her2 and the sub group

\begin{tabular}{|c|c|c|c|}
\hline Biomolecular. & & & P= 0.01 \\
\hline HER2 Status & & & \\
\hline Her2 =0 & $232(53,8)$ & $80(46,24)$ & \\
\hline Her2 =1 & $13(3)$ & 1 & \\
\hline Her2=3 & $187(43,2)$ & $92(53,17)$ & \\
\hline \multicolumn{2}{|c|}{ Biomoleculaire Subgroup } & \\
\hline $\begin{array}{c}\text { Luminal } \\
\text { (RH+,Her2-) }\end{array}$ & $157(36,34)$ & $48(27,8)$ & \\
\hline $\begin{array}{c}\text { (luminal/ } \\
\text { Her2+,Her2+) }\end{array}$ & $187(43,2)$ & $92(53,17)$ & \\
\hline $\begin{array}{c}\text { Triple negative } \\
\text { (TN) }\end{array}$ & $88(20,37)$ & $33(19,07)$ & \\
\hline
\end{tabular}

SG (Global Survival) Avg $=45.07$ months $[43.54$ to 45.81$]$ $(95 \%)$
Table 5: Toxicity related to zoledronic acid to adjuvant.

\begin{tabular}{|c|c|c|}
\hline Effets secondaires & Grade $\mathbf{1}$ et $\mathbf{2}$ & Grade3 et $\mathbf{4}$ \\
\hline $\begin{array}{c}\text { Ostéonécrose de la } \\
\text { mâchoire }\end{array}$ & 0 & \\
\hline $\begin{array}{c}\text { Syndrome pseudo } \\
\text { grippal }\end{array}$ & 0 & \\
\hline Algies osseuses & $0,6 \%(\mathrm{n}=2)$ & \\
\hline Hypocalcémie & $1,16 \%(\mathrm{n}=4)$ & \\
\hline Insuffisance rénal & 0 & \\
\hline Cardiaque & 0 & \\
\hline
\end{tabular}

We found that the pCR is much higher in the age group which is between (35-50 years) with $53.17 \%$ (Table 6). Those over 50 years in 2 nd position with $27.7 \%>$ from the young woman $<35$ years of pCR is $19 \%$, not statistically significant. The pCR was also in favor of the menopausal group in $51,4 \%$, and $48,55 \%$ in premenopausal women, statistically insignificant This could be explained by the mechanism that zoledronic acid could interact on a poor background estrogen stabilizing microenvironment with decreased tumor cell proliferation. The average duration of progression-free survival was also significantly in the subgroup (Luminal-Her2, Her2) to the triple negative. It is 45.18 months in the group (luminal - Her2 +) vs 38.95 in the triple negative group, As against the overall survival has improved in the 4 groups with 45.77 months for (luminal - Her2), 45.32 months for Her2 group, 44.37 months for luminal and 44.11 months for the TN group higher compared to the literature or overall survival of 30 months TN (Figures 5-10).

Table 6: Correlation between pCR and tumor characteristics.

\begin{tabular}{|c|c|c|c|}
\hline $\begin{array}{c}\text { Tumor } \\
\text { characteristics } \\
\text { (biopsy before } \\
\text { CT) }\end{array}$ & $\begin{array}{c}\text { Number of } \\
\text { patients (\%) }\end{array}$ & pCR, (\%) & p \\
\hline \multicolumn{3}{|c|}{ Age at diagnosis } & NS \\
\hline <35 ans & $89(20,6)$ & $33(19)$ & \\
\hline $35-50$ ans & $250(57,8)$ & $92(53,17)$ & \\
\hline$>50$ ans & $93(21,5)$ & $48(27,7)$ & \\
\hline \multicolumn{2}{|c|}{ Genital activity } & NS \\
\hline postmenopausal & $212(49,07)$ & $89(51,4)$ & \\
\hline premenopausa & $220(50,9)$ & $84(48,55)$ & \\
\hline \multicolumn{2}{|c|}{ BMI } & & P= 0,006 \\
\hline$<25 \mathrm{~kg} / \mathrm{m} 2$ & $171(39,58)$ & $118(68,2)$ & \\
\hline $25-30 \mathrm{~kg} / \mathrm{m} 2$ & $211(48,84)$ & $55(31,8)$ & \\
\hline$>30 \mathrm{~kg} / \mathrm{m} 2$ & $50(11,57)$ & 0 & \\
\hline
\end{tabular}




\section{Cancer Therapy \& Oncology International Journal}

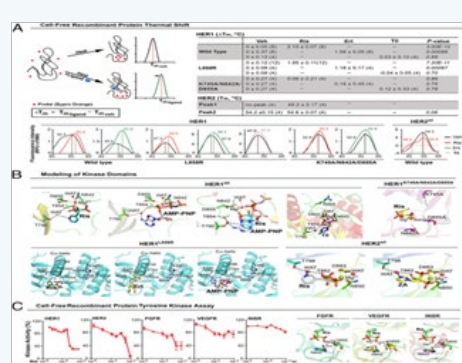

Figure 5: Inhibitor of tyrosine kinases by AZ (PNAS, November 2014).

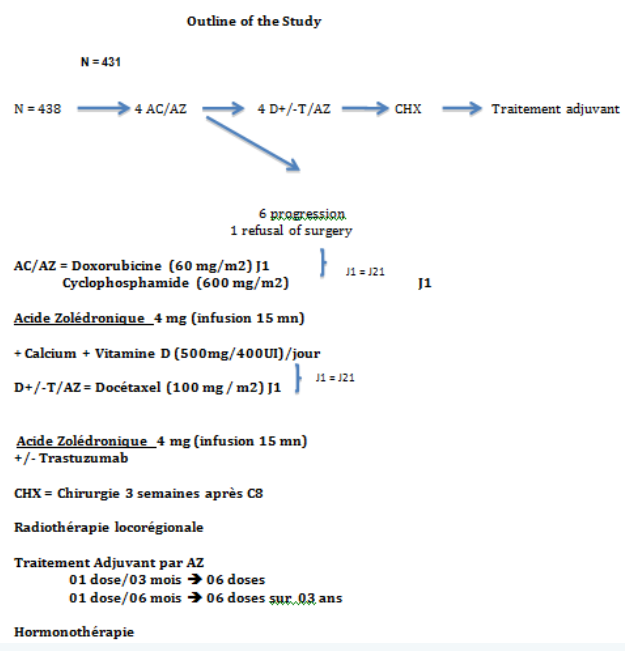

Figure 6: Outline of The Study.

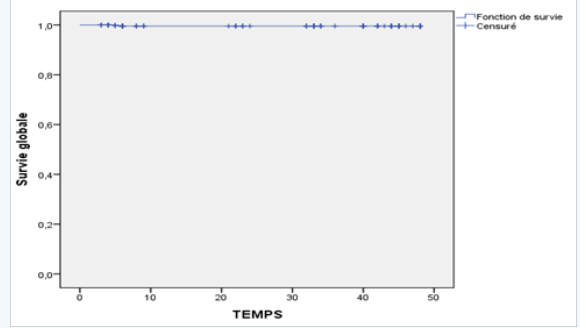

Figure 7: SG (Global Survival) Avg $=45.07$ months [43.54 to 45.81] $(95 \%)$

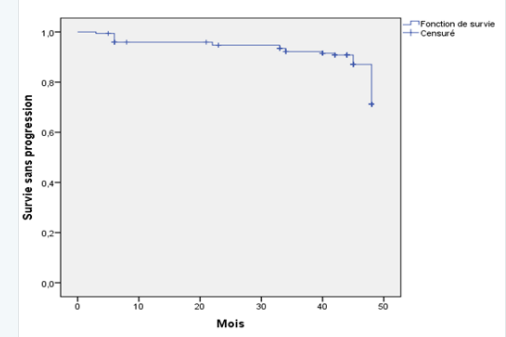

Figure 8: TTP (time to progression) $=44.81$ months $[44$ to 45.75] (95\%).

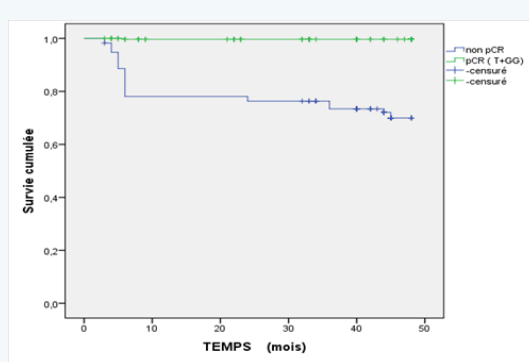

Figure 9: SG: No pCR pCR vs $=45.86$ months [45.59 to 46.13 ] vs 37.72 months [34.47 to 40.96 ] (95\%) $p=0.001$ (log rank test).

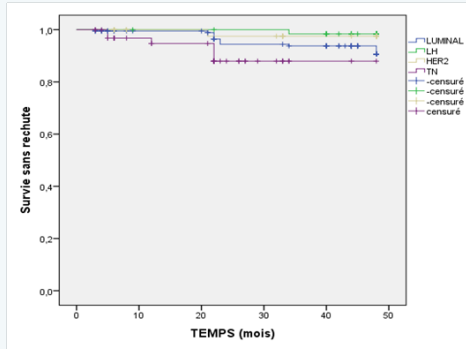

Figure 10: SG month: Luminal / Her2; luminal; Her2 vs TN = 45.18 months [45.15 to 46.21 ]; 45.26 months [45.03 to 46.50 ]; 44.18 months [ 40.06 to 45.30 ] vs 40.11 months [36.16 to 41.06 ] (95\%). $p=0.04$ Log Rank Test.

We found that there's been fewer events compared to the literature [6] 34 vs 53 . Local recurrence was $5 \%$ vs $15 \%$, against not by isolated bone recurrence when compared with Neoazure the study [6] 17 cases of bone recurrence.

a) The Patients who developed brain metastases had together bone in secondary locations $2.08 \%$ vs $11 \%$ in the literature [6].

b) The $2.08 \%$ of patients who have developed brain and bone metastases, had hormonal status be (ER +, PR +, Her2 +) in 1 case and negative hormonal status.

c) (ER - PR, Her2 -) in 8 cases, his patients did not complete histological response.

d) The Brain and bone were more relapses in the triple negative group.

e) The deaths were due to brain metastases.

f) Was observed in our study a difference in quality of life between (C1) to the admission of the patient, and after the (C8), we found general signs and a deterioration in the psychological condition to $\mathrm{C} 1$ in contrast to these general signs C8 and mental condition improves, up to 12 , and 24 months.

g) In our study there's a osteoprotecteur effect of zoledronic acid to neoadjuvant chemotherapy combined proven on BMD at the C1 and C8, with a gain of $26.39 \%$. Patients who were osteopenic and osteoporotic has the (C1) have switched to a normal BMD (C8) with effect protector 


\section{Cancer Therapy \& Oncology International Journal}

since followed after 48 months, no patient has developed fracture it with or without hormone therapy with a better quality of life.

Our results are correlated to literature associated with adjuvant hormone therapy and neoadjuvant, zoledronic acid may provide osteoprotecteur benefit by preventing the decrease in BMD and maintain a good quality of life for survival.

I. A New meta-analysis published by EBCTCG group in the journal The Lancet [7], on bisphosphonates (zoledronic acid) in the adjuvant setting have improved overall survival with decreased risk of metastatic relapse, especially bone, death linked to cancer and death from any cause.

\section{Conclusion}

Neoadjuvant chemotherapy with zoledronic acid in recent years has shown interesting properties in terms of clinical response, with increased pathologic complete response. PCR with zoledronic acid is increased according to the higher tumor grade and negative hormone status, but also molecular subtypes of breast cancer Her2. The importance of identifying predictors of pCR and therefore responder patients and not early responders to chemotherapy and zoledronic acid. With our study zoledronic acid showed a synergistic antitumor effect with doxorubicin situation neoadjuvant zoledronic. L'acide a good model ad hoc to evaluate in vivo efficacy in reducing tumor volume of an associated treatment chemotherapy.

The overexpression of Her2, provides better pathologic complete response after the addition of zoledronic acid, is consistent with the literature where the benefit of chemotherapy with anthracyclines seems mainly and only in Her2 positive patients, versus negative Her2, and zoledronic acid potentiates this. So the identification of specific biological factors in Her2 + tumors is important for complete response to neoadjuvant chemotherapy. The studies that have been published recently in the Proceedings of the American Academy of Sciences (PNAS) [811] demonstrating that bisphosphonates zoledronic acid namely the ability to block the abnormal growth signals transmitted via the HER receptors, these studies have shown that zoledronic acid may inhibit the tyrosine kinase even in case of secondary transfer and thereby potentiate and treat the breast cancer has become resistant to primary treatment. a. These Clinical results underline again the existence of a possible bone tumor effect and extra-bone zoledronic acid, independent of its bone antiresorptive activity.

This new understanding and confirmation of this mechanism lays the opportunity and promise of zoledronic acid for the prevention of relapse (metastases) and the treatment of many cancers characterized by these oncogenes (HER) in the occurrence of breast cancer.

\section{References}

1. Winter MC, I Holen, Coleman RE (2008) Exploring the antitumour activity of bisphosphonates in early breast cancer. Cancer Treat Rev 34: 453-475.

2. Mundy GR, Yoneda T, Hiraga T (2002) Preclinical pharmacology of zoledronic acid. Semin Oncol 2(6): 35-44

3. Mundy GR (2002) Metastasis to bone: causes, consequences and therapeutic Opportunities. Nat Rev Cancer 2(8): 584-593.

4. Rouzier R, Pusztai L, Delaloge S, Gonzalez-Angulo AM, Andre F, et al (2005) Nomograms to predict pathologic complete response and metastasis-free survival after-preoperative chemotherapy for breast cancer. J Clin Oncol 23(33): 8331-8339.

5. Abstract PD07-06: NEOZOTAC San Antonio breast cancer symposiumDecember 2012.

6. The effects of zoledronic acid to neoadjuvant. Adding chemotherapy on tumor response: exploratory evidence for live anti-tumor activity in breast cancer. British Journal of Cancer (2010) 1: 7.

7. EBCSG group bisphosphonates, bone, and breast cancer recurrence July 24,2015 .

8. Stachnik A, Yuen T, Iqbal J, Sgobba M, Gupta Y, et al. (2014) Repurposing of bisphosphonates for the prevention and therapy of no small cell lung, breast cancer. Proc Natl Acad Sci U S A 111(50): 17995-18000.

9. R. Colman. The effects of zoledronic acid to neoadjuvant Adding chemotherapy on tumor response: exploratory evidence for live antitumor activity in breast cancer.

10. Gunter von Minckwitz, Jens Uwe Blohmer, Serban Dan Costa, Carsten Denkert, Holger Eidtmann, et al. (2013) Response-Guided Neoadjuvant Chemotherapy for Breast Cancer. J Clin Oncol Off J Am Soc Clin Oncol 31(29): 36233630.

11. Colleoni M, Bagnardi V, Rotmensz N (2010) A nomogram based on the Expression of Ki-67, steroid hormone receptors status and number of chemotherapy courses to predict pathological. Complete preoperative chemotherapy after-response for breast cancer. Eur J Cancer 46: 22162224 
Your next submission with JuniperPublishers will reach you the below assets

- Quality Editorial service

- Swift Peer Review

- Reprints availability

- E-prints Service

- Manuscript Podcast for convenient understanding

- Global attainment for your research

- Manuscript accessibility in different formats

( Pdf, E-pub, Full Text, Audio)

- Unceasing customer service

Track the below URL for one-step submission http://juniperpublishers.com/online-submission.php 